\title{
The damage analysis of the reinforced concrete beam and the prestressed reinforced concrete beam
}

\author{
Milan Vaško ${ }^{1, *}$, Marián Handrik ${ }^{1}$, Matej Rác $^{1}$, Vladislav Baniari ${ }^{1}$, Ján Kortiš ${ }^{2}$, \\ L'uboš Daniel $^{2}$ \\ ${ }^{1}$ University of Žilina, Faculty of Mechanical Engineering, Department of Applied Mechanics, \\ Univerzitná 8215/1, 01026 Žilina, Slovak Republic \\ ${ }^{2}$ University of Žilina, Faculty of Civil Engineering, Department of Structural Mechanics, Univerzitná \\ 8215/1, 01026 Žilina, Slovak Republic
}

\begin{abstract}
The paper deals with the finite-element analysis of damage in reinforced concrete beam and prestressed reinforced concrete beam. The steel reinforcement is modeled using non-linear rebar elements and an elastoplastic model of the reinforcement is considered. The initial prestress is defined in the ropes that are used to create the prestressed reinforced concrete beam. These ropes are also modeled using non-linear rebar elements and the elastoplastic material model. Created computational model allows the damage modeling of the reinforced and pre-stressed reinforced concrete beams under static loading.
\end{abstract}

Keywords: reinforced concrete beam, prestressed reinforced concrete beam, rebar elements, FE analysis

\section{Introduction}

Concrete is the most used construction material for the construction of load-bearing structures in the world. Specific physical and mechanical properties of concrete must be considered when designing structures. Concrete has a relatively high compressive strength but low ductility and tensile strength (represents only about $10 \%$ of the compression strength). Concrete is reinforced to eliminate this deficiency. The most commonly used reinforcing material is steel and it is usually embedded passively in the concrete. In addition, a reinforcement based on glass, carbon or aramid fibers is used.

Prestressed concrete is a production technology in which a pressure stress independent of the external load is introduced into the concrete element by a mechanically tensioned reinforcement. This pressure stress totally or significantly reduces the unfavorable tensile stress caused by the external load. Bearer of prestressing is the elastic deformation of the rope (tendon). The tendon is stretched so much that its elastic deformations strain the concrete element by pressure. The combination of reinforcement and prestressing

\footnotetext{
* Corresponding author: milan.vasko@fstroj.uniza.sk

Reviewers: Robert Grega, Bohuš Leitner
} 
guarantees a longer life and load bearing capacity, which allows the possibility of designing smaller cross sections.

\section{Structural properties of concrete and reinforced concrete}

Concrete is a composite material that is made of stone, cement, water, additives and impurities. Some concrete properties are improved by additives and admixtures. Concrete properties are determined by its composition, method of production, transport, compacting, treatment, protection and proper maintenance. The most important features of structural concrete are mechanical properties and durability in the environment.

Concrete behaves almost as a linear elastic material at pressures up to $30 \%$ of concrete strength $R_{m C O N}$. When compressive stresses $(0.3-0.4) \cdot R_{m C O N}$ are reached the microcracks occur in contact of cement putty and stone crumbs. The microcracks further propagate along the surface of the grains with increasing pressure stress up to value of $0.6 \cdot R_{m} \mathrm{CON}$. Microcracks are beginning to expand into the cement putty and create a coherent system of microcracks if pressure exceeds the value of $0.6 \cdot R_{m \mathrm{CON}}$. Concrete plasticizing and permanent irreversible deformations of the structure have occurred since that moment.

The modulus of elasticity $E_{C O N}$ is the basic deformation characteristic of concrete. Hooke's law is valid for stresses up to about 30-40\% of short-term strength and $60 \%$ of tensile strength. However, this dependency is applied only for short-term load. Various factors affect the modulus of elasticity (water saturation, material properties of cement and stone crumbs, etc.) [1].

Reinforced concrete is a composite material in which the tension is transmitted by inserted reinforcing bars and pressure is transmitted by concrete. Coherence between the steel core and the hardened cement stone is expected. This stone with its strongly alkaline reaction creates a passive surface of the reinforcement and prevents corrosion [2].

\section{Prestressing reinforcement}

Prestressed concrete - thanks to a compression force in prestressed concrete cracks are found only limited or their size is small. The pressure reserve for load transfer is created by the formation of a prestress to better utilize the basic pressure properties of the concrete and eliminates the disadvantage of low tensile strength. Linear elastic material it becomes because the preload eliminates brittle tensile failure.

The prestressed beam is stiffer and consequently it has less ductility. The prestressing beams may be slimmer, with a smaller cross-sectional area and longer length due to these properties under the same requirements to deflections limit. The energy required for its breach is higher than for conventional reinforced concrete parts.

The prestressing reinforcement is an active element in prestressed concrete. Its stress is generated by mechanical tension. This is independent of the structure deflection or the external load. The required mechanical and physical properties of the concrete reinforcement are obtained by suitable chemical composition of the steel. Hot-formed rods of conventional carbon steel with a maximum carbon content of $0.22 \%$ are used. Highstrength wires, tendons and rods are used as prestressing reinforcements in construction practice. The basic requirement of the prestressing reinforcement is the largest elastic deformation [3-7].

Additional mechanical cold forming can be used to improve the strength properties of steel. The steel strength $R_{m}=1400-2000 \mathrm{MPa}$ (ultimate stress) can be achieved by this molding. The high-strength prestressing reinforcement must also have a guaranteed tensibility $\left(\varepsilon_{p u}\right.$ up to $\left.3.5 \%\right)$. The tensibility of the reinforcement is one of the most 
significant properties of steel. This represents the ability of reinforcement's large deformation without significant decrease in stresses $[1,8]$.

The properties of the concrete reinforcement and the prestressed reinforcement can be compared in Fig. 1. Yield stress $R_{e}$ is basic characteristic of concrete reinforcement produced by the conventional hot-rolled steel. The reinforcement cannot be used above this value due to the subsequent large longitudinal deformations $\varepsilon_{s}$. These transformations cause large plastic deformations of the reinforcement, which cause the loss of cohesion with the concrete. Concrete reinforcements produced by cold drawing have a non-significant yield stress value therefore $\sigma_{0.2}$ is used $[1,3,9]$.

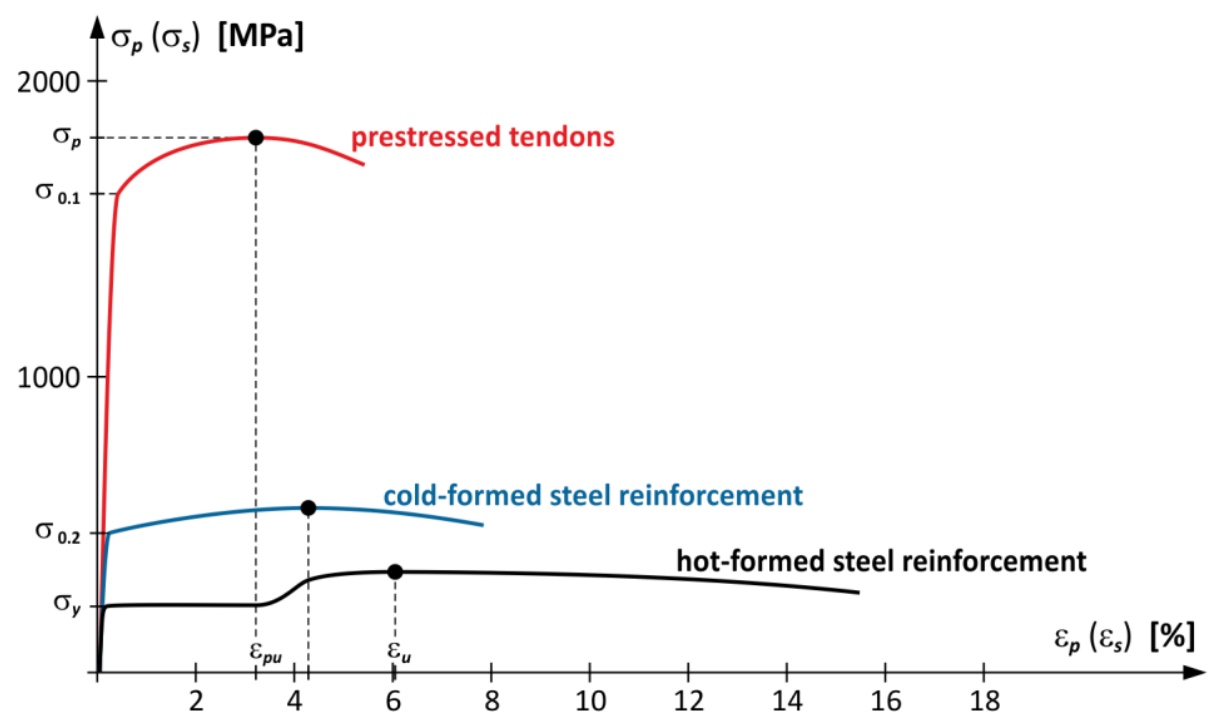

Fig. 1. Properties of the concrete reinforcement and the prestressed reinforcement

\section{Numerical experiments}

The basic dimensions of the tested beam are shown in Fig. 2. The total beam length is $3600 \mathrm{~mm}$ and the theoretical distance between the supports of the beam is $3300 \mathrm{~mm}$. The pressure acting on the beam is $1.4 \mathrm{MPa}[10]$.

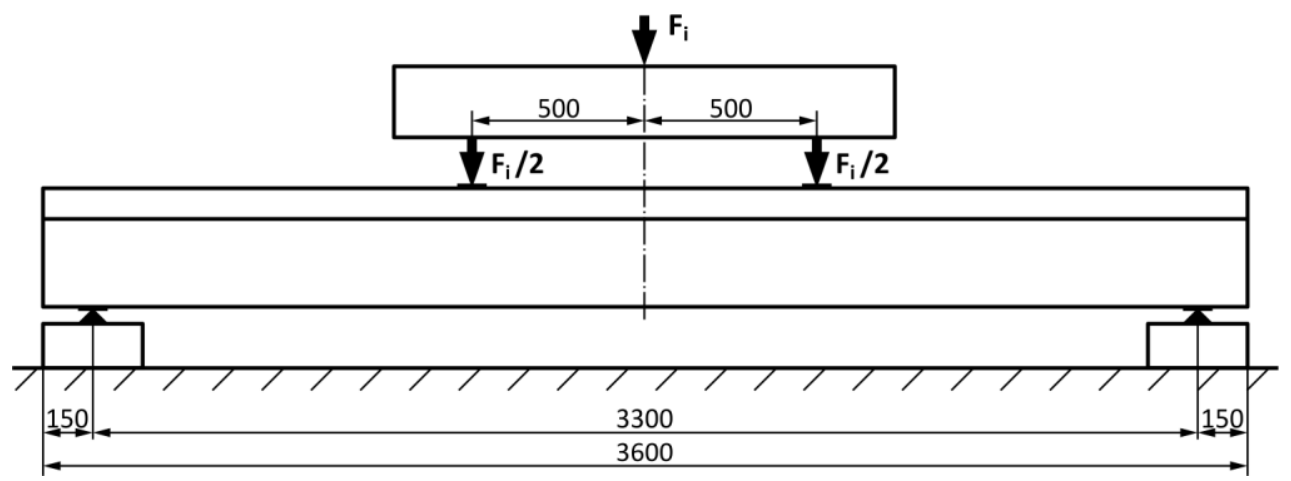

Fig. 2. The basic dimensions of the tested beam 


\subsection{FE model creating}

The beam model was created in ADINA software [11, 12]. Parts 1 and 3 are not important for calculation, so they have a smaller mesh density. The material model of the concrete is assigned to the part 2 and it is meshed with 3D solid 8-node elements (Brick Elements) with the size of $20 \mathrm{~mm}$. On the contact area of these parts is created so-called Glue Mesh. This feature allows connecting areas of the model with different types of mesh (Fig. 3).

The pressure is applied to two areas of size $60 \times 350 \mathrm{~mm}$. Boundary conditions were defined in the support locations so that the beam is statically determinate. The rotation in all 3 axes was discarded before the calculation and it was necessary to specify boundary conditions for translational movement. All three translational movements in $x, y$ and $z$ axes were removed at the point " $\mathrm{C}$ " and translational movement in the $\mathrm{z}$-axis was removed at the point "B".

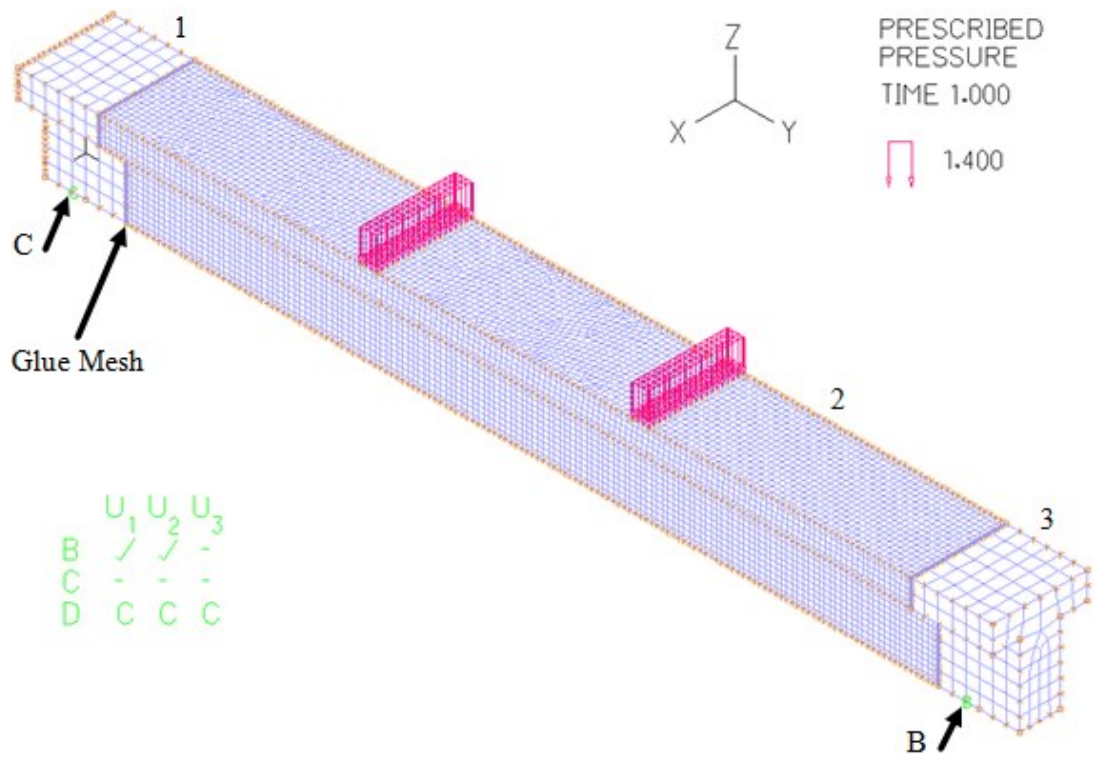

Fig. 3. Meshed beam model created in ADINA

The reinforcement was created using geometric lines that were subsequently defined as Truss-Rebars. The "Rebar element" is used to create trussed elements and limitations between beam nodes and fixed elements. The reinforcement used in the beam model is shown in Fig. 4 [12, 13].

Various material models were used in the model (for concrete, steel reinforcement and prestressed steel reinforcement). To verify the strength and fatigue properties of concrete reinforcement, an experimental test was made at the Department of Applied Mechanics (Faculty of Mechanical engineering, University of Žilina). The result of the measurement was the determination of the strength characteristics and the working diagram of the reinforcement $[10,14]$.

The constants for the material model of the concrete reinforcement and the prestressing reinforcement are shown in Table 1. 


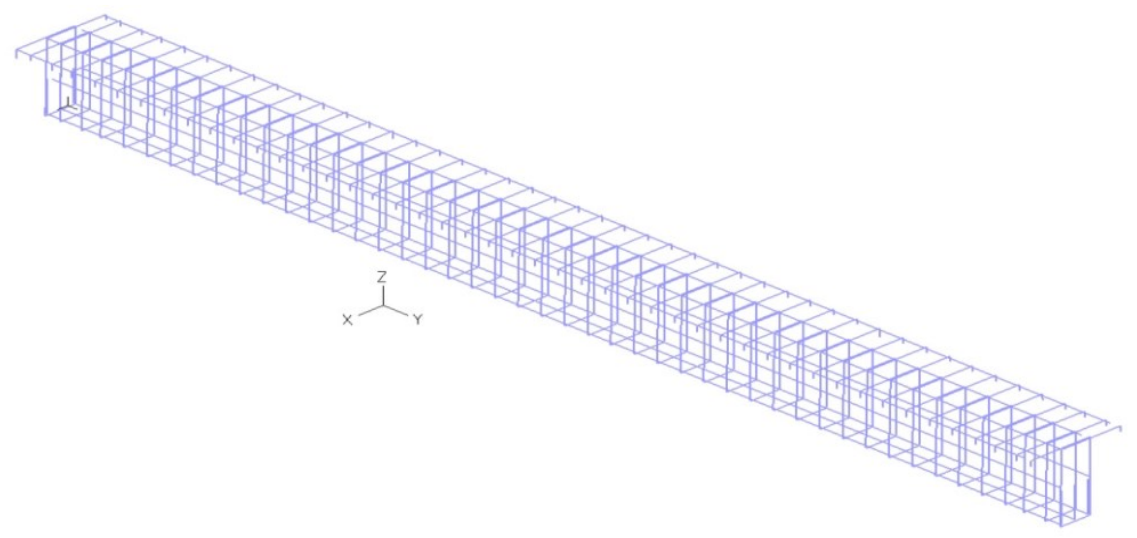

Fig. 4. Steel reinforcement in the model of reinforced concrete beam

Table 1. Constants of the concrete reinforcement and prestressing reinforcement material model

\begin{tabular}{|l|c|c|}
\hline & $\begin{array}{c}\text { Concrete } \\
\text { reinforcement }\end{array}$ & $\begin{array}{c}\text { Prestressing } \\
\text { reinforcement }\end{array}$ \\
\hline Young's Modulus [MPa] & 210000 & 195000 \\
\hline Poissnos's Ratio [-] & 0.3 & 0.3 \\
\hline Initial Yield Stress [MPa] & 500 & 1600 \\
\hline Strain Hardening Modulus [MPa] & 5000 & 2500 \\
\hline Max. Allowable Effective Plastic Strain [-] & 0.02 & 0 \\
\hline
\end{tabular}

\subsection{FE simulation of the reinforced concrete beam}

The beam with concrete material model, which is loaded by the pressure of $1.4 \mathrm{MPa}$ (i.e. $29.4 \mathrm{kN}$ for each area) is shown in Fig. 5. The stress at the top of the beam is approximately $6.6 \mathrm{MPa}$ and at the bottom is approximately $4 \mathrm{MPa}$. Deflection of the beam is shown in Fig. 6; the maximum deflection reached $1.2 \mathrm{~mm}$.
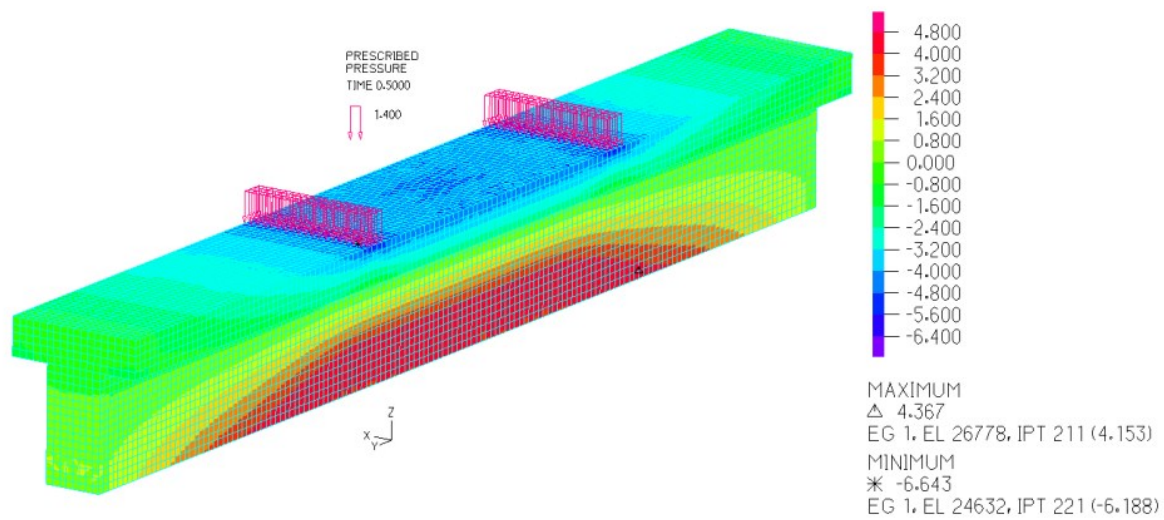

Fig. 5. FEM analysis of stresses in beam model 


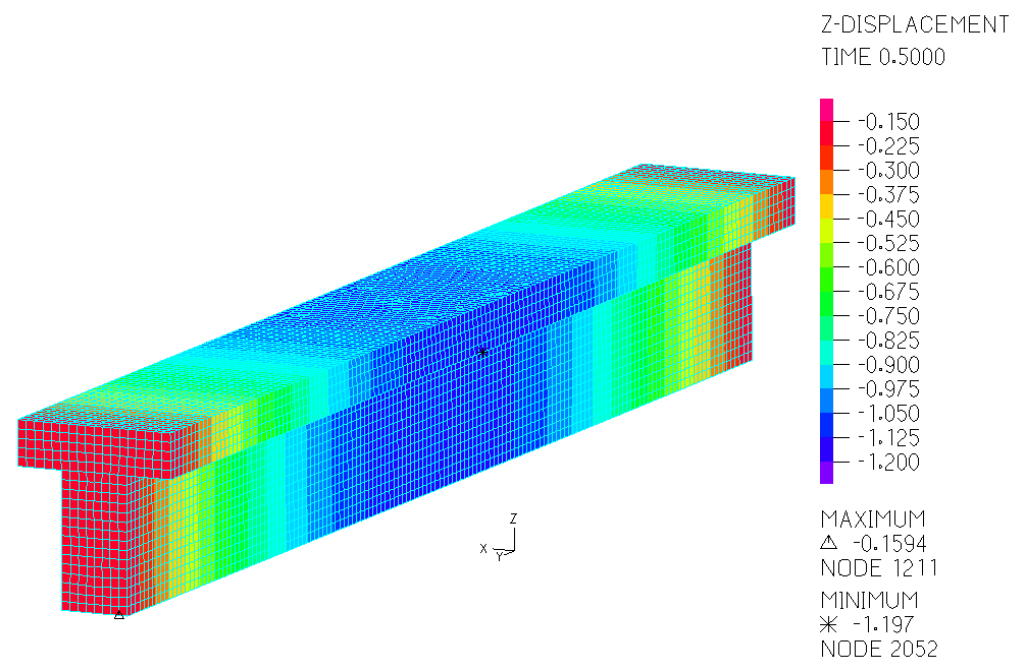

Fig. 6. Deflection of the beam in $z$ axis

Deflection of the beam at the point of maximum deflection as a function of acting compressive force is shown in Fig. 7. Displacement curve had a linear course up to the value of the applied pressure of $1.12 \mathrm{MPa}$. When this pressure was exceeded, the beam began to crack and there was started a crack propagation. This caused a weakening of the beam and there was a greater and more rapid increase in the value of the beam deflection.

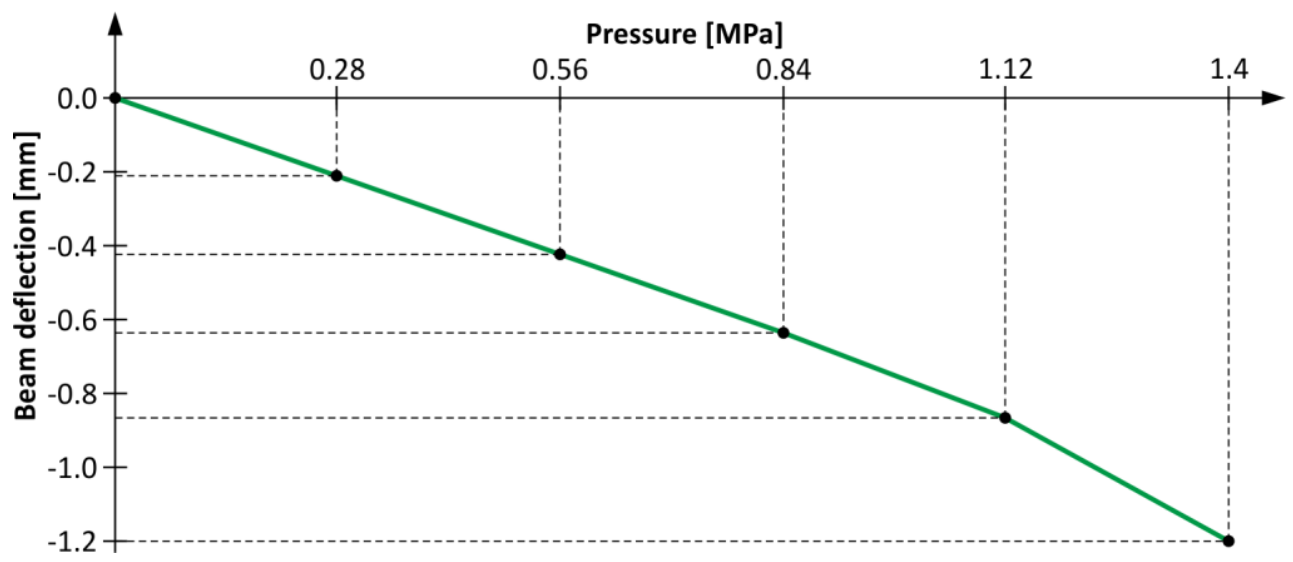

Fig. 7. Deflection of the beam at the point of maximum deflection

Similar values were reported in the FEM analysis of the beam compared to the static beam test $[10,15,16]$. Beam deflection of $1.4 \mathrm{~mm}$ was measured in a static test in the same place as in FEM analysis. Figs. 8 and 9 show the formation of cracks and the subsequent extinction of the elements in the FEM simulation of the static test. After the extinction of the first elements the calculation further converged, even though part of the beam was located in the plastic zone due to the reinforcement that carried the pressure load acting on the beam $[17,18]$. 


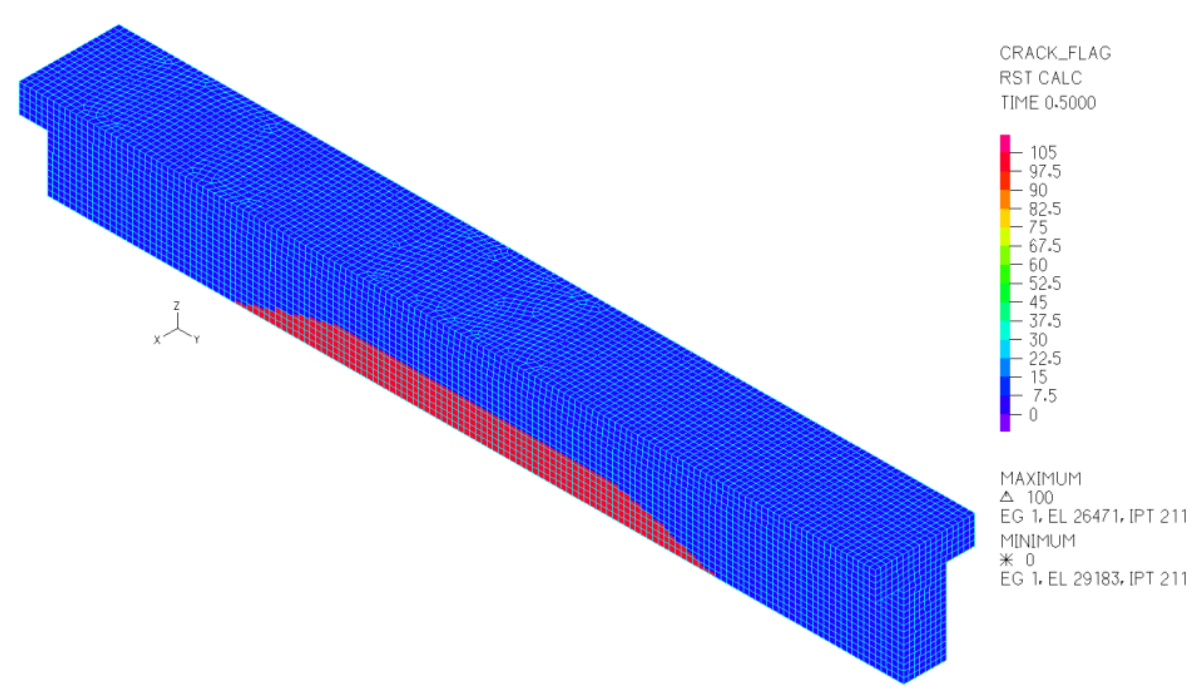

Fig. 8. Formation of cracks and the subsequent extinction of the elements

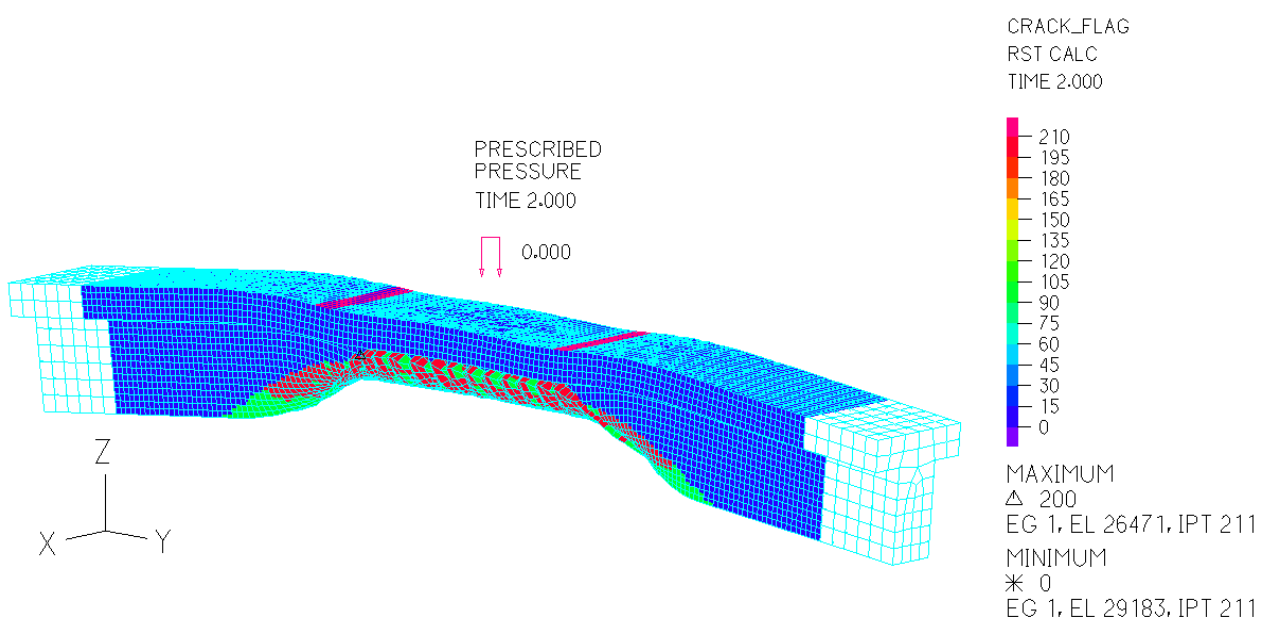

Fig. 9. Extinction of the beam elements

\subsection{FE simulation of prestressed concrete beam}

The prestress in the beam was created by adding two prestressed ropes. The ropes were loaded with a preload which was recalculated with an initial pressure of $1.5 \mathrm{MPa}$. The number of prestressed ropes, their position and dimensions were calculated based on the beam's bearing capacity and expected life at the request of dimensional compliance with the above tested beam (Fig. 10) [4, 19, 20]. 


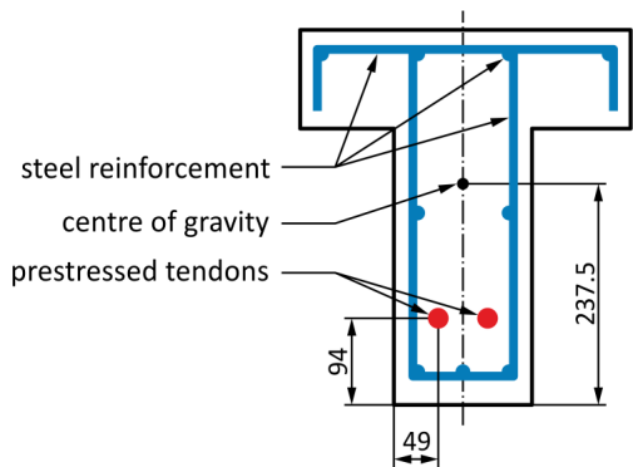

Fig. 10. Distribution of the reinforcement and prestressed tendons in the beam

The prestressed ropes cause stress at the upper part of the beam about $1.7 \mathrm{MPa}$ and at the bottom -11 MPa. The prestressing of the tendons has been calculated so that no cracking of the concrete occurs in this state. The stresses in the center of the beam at the top reached 1.6 $\mathrm{MPa}$ and $-9.4 \mathrm{MPa}$ at bottom. FE simulation of the prestressed beam was done in the same way as the reinforced concrete beam test (Fig. 11). At places of the highest stress concentrations the stress values are 1.75 $\mathrm{MPa}$ and $-11.5 \mathrm{MPa}$.

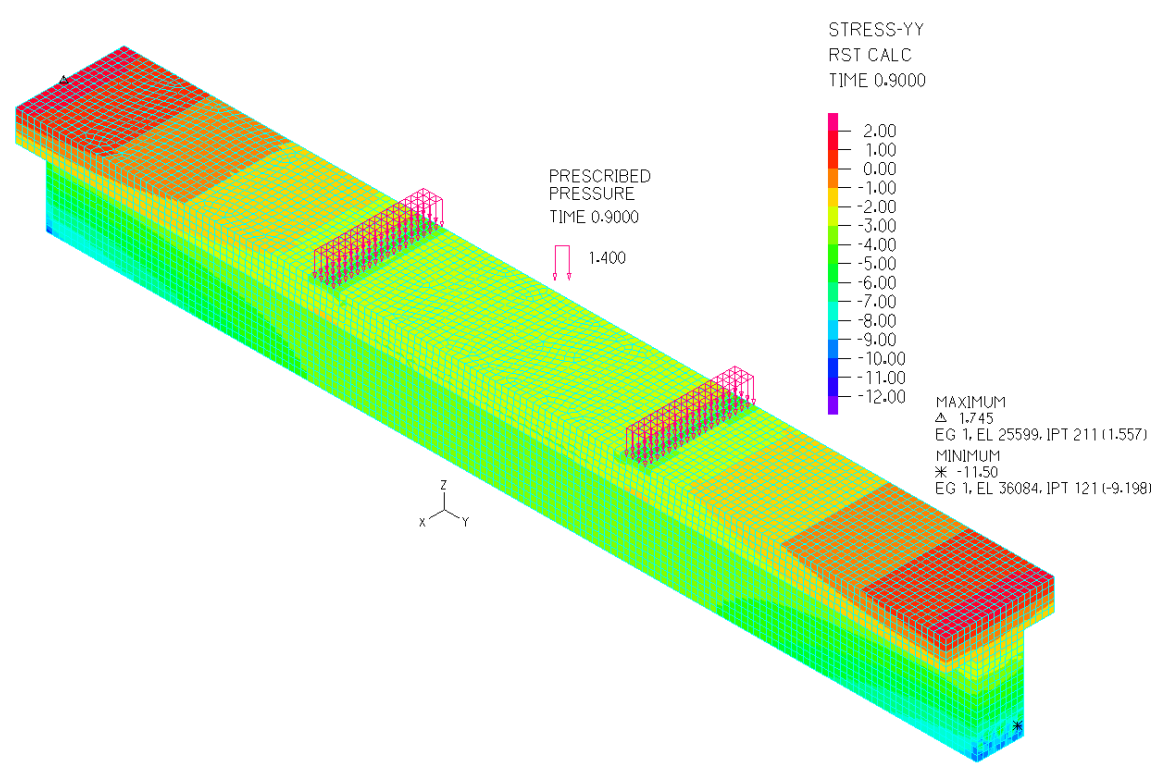

Fig. 11. FEM simulation of the prestressed beam

Further stress concentrations have arisen at locations where parts of a beam with different types of mesh are joined. The stresses at these points reached the value of $1.7 \mathrm{MPa}$ and $-10.7 \mathrm{MPa}$. At the center of the beam the maximum stress at the top of the beam reached -2.6 $\mathrm{MPa}$ and at the bottom -3.5 $\mathrm{MPa}$.

FEM simulation showed that the deflection of the unloaded beam was $1.2 \mathrm{~mm}$ due to prestressed ropes. The deflection value was changed when an external load began to work. Upon reaching a maximum pressure value of $1.4 \mathrm{MPa}$ the beam deflection reached value of $0.2 \mathrm{~mm}$. The deflection of the beam in the negative direction of the $z$ axis has not occurred due to the prestressed ropes. When the maximum pressure is applied, the beam is almost in the equilibrium position and there is no violation of the beam. 


\section{Conclusions}

FEM simulation of reinforced concrete beam and prestressed beam, their mutual comparison and comparison with the experimental static test of the reinforced concrete beam was solved with in this paper. Comparison of the results showed that the prestressed beam carries a higher load and has a smaller deflection values than a reinforced concrete beam of the same dimensions. The formation of cracks is greatly reduced in the prestressed beam as opposed to the reinforced concrete beam. FEM analysis confirmed that the prestressed reinforcement in beams plays a major role.

As mentioned above, the number of prestressed tendons, their position and dimensions were calculated based on the beam's bearing capacity and expected life at the request of dimensional compliance with the reinforced concrete beam. FEM analysis also showed that by varying the number of prestressed ropes and their positions it is possible to create different variants of the prestressed beams according to their specific bearing and dimensional requirements.

This work is supported by VEGA grant No. 1/0795/16 "Development of effective methods for correction and optimization of coupled mechanical system" and work was supported by the Slovak Research and Development Agency under the contract No. APVV-0736-12.

\section{References}

1. I. Havran, Prestressed concrete. [in Slovak] (STU Bratislava, Bratislava, 2010)

2. L. Vítek, Building materials. [in Czech] (VUT Brno, Brno, 2012)

3. A. Vaško, J. Belan, Fatigue tests of nodular cast iron at low and high frequency cyclic loading. Materials Today-Proceedings 4 (5), 5985-5988 (2017)

4. P. Kopas, L. Jakubovičová, M. Vaško, M. Handrik, Fatigue Resistance of Reinforcing Steel Bars. Procedia Engineering 136, 193-197 (2016)

5. G. Domek, A. Kołodziej, Design of the tendon structure in timing belts. Procedia Engineering 136, 365-369 (2016)

6. R. Grega, J. Krajňák, L. Žul'ová, G. Fedorko, V. Molnár, Failure analysis of driveshaft of truck body caused by vibrations. Engineering Failure Analysis 79, 208-215 (2017)

7. M. Bara, T. Kmita, J. Korzekwa, Microstructure and properties of composite coatings obtained on aluminium alloys. Archives of Metallurgy and Materials 61 (3), 1107-1112 (2016)

8. W. Piekarska, M. Kubiak, Z. Saternus, Numerical simulation of deformations in T-joint welded by the laser beam. Archives of Metallurgy and Materials 58 (4) 1391-1396 (2013)

9. J. Stancek, V. Bulej, Design of driving system for scissor lifting mechanism. Acad. J. of Manufacturing Eng. 13, 38-43 (2015)

10. A. Čavojcová, Resistance enhancing of concrete constructions stressed by cyclic loading. [Dissertation work, in Slovak], 130 p. (2016)

11. K. J. Bathe, Finite Element Procedures. (Prentice Hall, New Jersey, 1982)

12. ADINA, Theory and Modelling Guide, Vol. III, CFD and FSI. [help manual]. (2017)

13. L. Jakubovičová, M. Sága, Computational analysis of contact stress distribution in the case of mutual stewing of roller bearing rings. Novel Trends in Production Devices and Systems, Applied Mechanics and Materials 474, 363-368 (2014) 
14. Z. Stankovičová, V. Dekýš, P. Novák, Time average synchronization in thermoelastic stress analysis. Procedia Engineering 136, 204-210 (2016)

15. P. Pastorek, P. Novák, P. Kopas, M. Močilan, Finite element analysis of bond behavior in a steel reinforced concrete structure strengthened carbon fibre reinforced polymer (CFRP) strips. Metalurgija 56 (3-4), 405-408 (2017)

16. M. Žmindák, P. Novák, V. Dekýš, Analysis of bond behaviour in strengthened reinforced concrete beam with carbon fiber reinforced polymer lamella. MATEC Web of Conferences 107 (UNSP 00045), 1-7 (2017)

17. M. Handrik, P. Kopas, V. Baniari, M. Vaško, M. Sága, Analysis of stress and strain of fatigue specimens localised in the cross-sectional area of the gauge section testing on bi-axial fatigue machine loaded in the high-cycle fatigue region. Procedia Engineering 177, 516-519 (2017)

18. A. Sapietová, V. Dekýš, M. Sapieta, P. Pecháč, Application of computational and design approaches to improve carrier stability. Procedia Engineering 96, 410-418 (2014)

19. B. Leitner, The procedure of fatigue damage estimation for mechanical structures under service loading. Transport Means 2014, 54-58 (2014)

20. R. Halama, P. Macura, L. Pečenka, F. Fojtík, M. Šofer, Experimental Analysis of Residual Stresses in Backup Roll and FE solution. Experimental stress analysis, $49^{\text {th }}$ Int. Scient. Conf. on Experimental Stress Analysis, 85-90 (2011) 